\title{
'Looking as Little Like Patients as Persons Well Could': Hypnotism, Medicine and the Problem of the Suggestible Subject in Late Nineteenth-Century Britain
}

\author{
TERI CHETTIAR* \\ Department of History, Northwestern University, 1881 Sheridan Road, Evanston, \\ IL, 60208-2220, USA
}

\begin{abstract}
During the late nineteenth century, many British physicians rigorously experimented with hypnosis as a therapeutic practice. Despite mounting evidence attesting to its wide-ranging therapeutic uses publicised in the 1880 s and 1890 s, medical hypnosis remained highly controversial. After a decade and a half of extensive medical discussion and debate surrounding the adoption of hypnosis by mainstream medical professionals - including a thorough inquiry organised by the British Medical Association - it was decisively excluded from serious medical consideration by 1900. This essay examines the complex question of why hypnosis was excluded from professional medical practice by the end of the nineteenth century. Objections to its medical adoption rarely took issue with its supposed effectiveness in producing genuine therapeutic and anaesthetic results. Instead, critics' objections were centred upon a host of social and moral concerns regarding the patient's state of suggestibility and weakened 'will-power' while under the physician's hypnotic 'spell'. The problematic question of precisely how far hypnotic 'rapport' and suggestibility might depart from the Victorian liberal ideal of rational individual autonomy lay at the heart of these concerns. As this essay demonstrates, the hypnotism debate was characterised by a tension between physicians' attempts to balance their commitment to restore patients to health and pervasive middle-class concerns about the rapid and ongoing changes transforming British society at the turn of the century.
\end{abstract}

Keywords: Hypnosis, Suggestibility, Doctor-Patient Relations, Victorian Medicine, Psychical Research

On 28 March 1890, more than sixty leading British medical men gathered in a surgical theatre in Leeds to observe Dr J. Milne Bramwell operate on seven hypnotized patients. Audience members were both astonished and gratified that none of the patients - men and women of varying ages and suffering from different complaints - appeared to

* Email address for correspondence: terichettiar2011@u.northwestern.edu 
experience pain either during or after surgery. One contributor to The Lancet noted that the patients 'look[ed] as little like patients as persons well could, giving neither by their manners or expression the slightest suggestion - except when external dressings were visible - that they had suffered or were suffering from, in some instances, extensive surgical interference'. ${ }^{1}$ At the close of each operation, Bramwell administered 'healing suggestions' which he anticipated would bring about 'very rapid healing'. ${ }^{2}$ The physicians in attendance considered the demonstration so 'marvellously successful' that when Pridgin Teale, a Fellow of the Royal Society, proclaimed that he felt 'sure that the time has now come when we shall have to recognise hypnotism as a necessary part of our study', his vote 'was carried by loud acclamations'. 3

Less than six months after Dr Bramwell's well-received hypnotic demonstration, a committee was appointed by the British Medical Association to investigate 'the nature of the phenomena of hypnotism; its value as a therapeutic agent; and the propriety of using it' ${ }^{4}$ The committee presented its positive findings at the BMA's annual meetings in 1892 and 1893, stating that its extensive experimental research showed that hypnotism 'was frequently effective in relieving pain, procuring sleep, and alleviating many functional ailments' ${ }^{5}$ Yet, in spite of the committee's enthusiasm for hypnotism as a mode of therapy, the BMA decided against adopting its recommendation for further investigation and the committee was disbanded. Although the experimental evidence attesting to hypnotism's many therapeutic uses continued to mount over the course of the $1890 \mathrm{~s}$ - and was published by some of Britain's most prominent physicians - hypnotism was never accepted into the mainstream medical profession's therapeutic canon. ${ }^{6}$ While medical interest in hypnotism never entirely ceased during the decades that followed - a minority of practitioners persisted in using hypnotism to treat a variety of 'functional' disorders - most members of the medical community regarded medical hypnotism with profound suspicion.

This essay examines the vexed question of why hypnotism was not taken up as a therapeutic practice by the British medical profession by focusing on the context for, and terms of, the decisive medical debate at the end of the nineteenth century. For, given the abundant evidence for hypnotism's wide-ranging therapeutic effects, physicians' objections to its adoption following Bramwell's demonstration rarely took issue with its supposed effectiveness in producing genuine therapeutic results. Instead, as this essay will argue, critics' objections were centered upon a host of social and moral concerns regarding the patient's state of suggestibility and weakened 'will-power' while under the physician's hypnotic 'spell'. Furthermore, an examination of physicians' discussions of

1 'Demonstration of Hypnotism as an Anaesthetic During the Performance of Dental and Surgical Operations', The Lancet, 135, 3475 (5 April 1890), 771-2: 772.

2 Ibid., 772.

3 Ibid., 772.

${ }^{4}$ C. Lloyd Tuckey, Treatment by Hypnotism and Suggestion, or Psycho-Therapeutics (New York: G.P. Putnam's Sons, 1907), 411. The BMA appointed Sir William Broadbent, Sir William Gairdner, and Drs Clouston, Drummond, Kingsbury, Needham, Connolly Norman, Suckling, Hack Tuke, Outterson Wood and Yellowlees.

5 Ibid., 412.

${ }^{6}$ While hypnotism was largely excluded from mainstream medical practice by the end of the nineteenth century, it was not wholly abandoned in medical experimentation and treatment. Its use resurfaced especially during the First World War in the treatment of shell shock. It should be noted, however, that by the second decade of the twentieth century, many practitioners of medical hypnotism had become very interested in psychological speculations concerning the existence of an unconscious mind (and unconscious conflicts) as the basis for understanding how hypnotism worked. For a brief account of the use of hypnotism as a psychiatric treatment during the First World War; see Ben Shephard, A War of Nerves (Cambridge, MA: Harvard University Press, 2001). 
hypnotism published in medical journals and textbooks reveals that their concerns about the nature and effects of hypnotic suggestibility were embedded in a specific set of middleclass anxieties about what was increasingly referred to as 'modern' life. The problematic question of precisely how far hypnotic 'rapport' and suggestibility might depart from - and even subvert - the Victorian liberal ideal of rational individual autonomy - widely held up as the basis for harmonious collective existence - lay at the heart of these concerns. As this essay will demonstrate, the hypnotism debate was characterised by a tension between physicians' attempts to balance their commitment to restore patients to health and pervasive middle-class concerns about the rapid and ongoing changes transforming British society at the turn of the century.

Recent examinations of hypnotism in nineteenth-century Britain and Europe have departed from the earlier intellectual historical focus on the theoretical continuities that existed from Mesmer to Freud, ${ }^{7}$ and instead considered social, cultural and professional concerns surrounding physicians' support for hypnotism as a therapeutic practice. Alison Winter's examination of mesmerism's decline in the mid-nineteenth century argues for the centrality of physicians' professional concerns about the regulation of medical practice. ${ }^{8}$ While Winter brings attention to the importance of specific mid-century concerns over the creation of a coherent university-educated profession, her treatment of mesmerism's 'afterlife' stresses similarities between mesmerism and a variety of late nineteenth-century projects - chiefly, hypnotism, spiritualism and psychoanalysis - and overlooks the extent to which medical responses to hypnotism in the 1890 s were animated by a very specific set of therapeutic and moral concerns. As this essay suggests, participants in the late nineteenth-century hypnotism debate were chiefly concerned not with the regulation of hypnotic practice in the interest of professionalisation, but with the regulation of hypnotism's potentially problematic effects.

Pamela Thurschwell, J.P. Williams, Daniel Pick, Joel Eigen and Mary Leighton have all illuminated the many problematic cultural associations with hypnotism and hypnotic trance states in the late nineteenth century. ${ }^{9}$ In fact, the imagined dangers of hypnotic suggestibility were so deeply embedded that even the supporters of medical hypnotism felt compelled to urge for the introduction of legal restrictions. As physicians almost unfailingly linked hypnotism to a host of perceived social problems in Britain at the turn of the century, the hypnotism controversy cannot be understood outside of the

\footnotetext{
${ }^{7}$ Alan Gauld, A History of Hypnotism (Cambridge: Cambridge University Press, 1992); Adam Crabtree, From Mesmer to Freud: Magnetic Sleep and the Roots of Psychological Healing (New Haven: Yale University Press, 1993). Both Gauld and Crabtree trace the origins of modern 'psychological healing' to Mesmer, a century before modern ideas of consciousness were beginning to be articulated.

${ }^{8}$ Alison Winter, Mesmerized: Powers of Mind in Victorian Britain (Chicago: University of Chicago Press, 1998).

${ }^{9}$ Pamela Thurschwell, Literature, Technology, and Magical Thinking, 1880-1920 (Cambridge: Cambridge University Press, 2001); J.P. Williams, 'Psychical research and psychiatry in late Victorian Britain: trance as ecstasy or trance as insanity', in W.F. Bynum, R. Porter and M. Shepherd (eds), The Anatomy of Madness: Essays in the History of Psychiatry, Vol. 1 (London and New York: Tavistock, 1985), 233-54; Daniel Pick, Svengali's Web: The Alien Enchanter in Modern Culture (New Haven: Yale University Press, 2000); Joel Eigen, Unconscious Crime, Mental Absence and Criminal Responsibility in Victorian London (Baltimore and London: The Johns Hopkins University Press, 2003); M.E. Leighton, “Hypnosis Redivivus”: Ernest Hart, the British Medical Journal, and the Hypnotism Controversy', Victorian Periodicals Review, 34, 2 (2001), 104-27. Hypnotism functioned as an important metaphor for a variety of social dangers in the 1890s. Thurschwell argues that the journalistic treatment of Oscar Wilde's prosecution for 'gross indecency' was embedded in a rich discourse concerning the dangers of hypnotic influence. Pick argues that George Du Maurier's Trilby was widely celebrated in the 1890 s because it articulated a pervasive fear that as individuals of tremendously disparate backgrounds came into close contact, networks of unconscious influence might develop and end in disaster.
} 
social and cultural context of instability and uncertainty about the direction of social change that dominated the 1890s. While this growing body of literature on hypnotism and psychotherapy in Britain acknowledges the richly problematic social and cultural associations with the hypnotic trance and troubling intimacy associated with hypnotic rapport, it overlooks late Victorian medical efforts to purge hypnotism of its morally questionable and anxiety-inducing associations.

Studies of hypnotic practice in France, Germany and the Austro-Hungarian Empire by Ruth Harris, Anne Harrington, Heather Wolffram and Emese Lafferton illuminate the unique nature of the medical hypnotism controversy in Britain. In late nineteenthcentury Britain, hypnotism bore fewer immediate and irrefutable associations with occult or spiritualistic practices than it did in Germany and Austria-Hungary because divisions between lay and professional practice were more stable, and there was far less bitter antagonism stemming from competing schools of thought than there was in France. ${ }^{10}$ As Heather Wolffram has shown, late nineteenth-century German medical hypnotists needed to distance themselves from prominent associations with such dubious figures as the itinerant hypnotist performer and the dabbler in occultism. In late nineteenth-century Britain, by contrast, the practices and phenomena long associated with spiritualism and the occult were in the process of being 'sanitised' by a wide variety of individuals, many of whom belonged to the newly formed Society for Psychical Research (SPR). Studies of the psychological aspects of hypnotism by psychical researchers Edmund Gurney and Frederick W.H. Myers beginning in the 1880 s were part of a move to purge hypnotism of its 'supernatural' associations, and to situate it firmly within the naturalistic purview of science. Although hypnotism's nineteenth-century heritage was mixed, British medical professionals were, in large measure, very open to its acceptance as a safe and reliable therapeutic technique in the early 1890s. There was an attitude of openness to its medical uses that was unmatched in the immediately preceding decades.

The late nineteenth-century debate over the medical adoption of therapeutic hypnotism in Britain has received surprisingly little attention from historians. This essay examines discussions of therapeutic hypnotism in British medical journals in the late nineteenth century, as well as the textbooks on hypnotism published by physicians in support of its use. ${ }^{11}$ Medical journals throughout the latter half of the nineteenth century served not only to make new research public and to record and reflect physicians' opinions, but also functioned effectively to define the profession's social role. Although physicians' positions in the debate were undoubtedly motivated by a variety of non-professional concerns, the views they expressed in public discussion constituted in part a deliberate attempt to both construct and make sense of the profession's relationship to the public. As such, the

\footnotetext{
${ }^{10}$ Ruth Harris, Murders and Madness: Medicine, Law, and Society in the Fin de Siècle (Oxford: Clarendon Press, 1989); Anne Harrington, 'Hysteria, hypnosis, and the lure of the invisible: the rise of neo-mesmerism in Fin-de-Siècle French psychiatry', in W.F. Bynum, Roy Porter and M. Shepherd (eds), The Anatomy of Madness, Vol. III (London: Routledge, 1988), 226-46; Heather Wolffram, “An Object of Vulgar Curiosity”: Legitimizing Hypnosis in Imperial Germany', Journal of the History of Medicine and Allied Sciences (November, 2010), online: http://jhmas.oxfordjournals.org/content/early/2010/11/08/jhmas.jrq072, accessed 10 July 2011; Emese Lafferton, 'Murder by hypnosis? Altered states and the mental geography of science', in Roberta Bivins and John V. Pickstone (eds), Medicine, Madness and Social History (Basingstoke: Palgrave MacMillan, 2007), 182-96.

${ }^{11}$ I have also surveyed the literature on hypnotism published through the Society for Psychical Research. Together, these sources comprise the vast majority of the scientific literature published on hypnotism in Britain in the late nineteenth and early twentieth centuries. Additionally, I have examined archived BMA minutes held at the Wellcome Library and SPR archival materials held at Trinity College, Cambridge.
} 
medical discussion of hypnotism provides a crucial entry-point not only for understanding physicians' attempts to define their standing as middle-class arbiters of the social good but also as a lens through which to view a much broader set of issues and anxieties about 'modern' British life at a key moment of wide-ranging social and cultural change at the end of the nineteenth century.

\section{Hypnotism Returns to Britain: The Context for the Medical Debate}

In 1889, when Charles Lloyd Tuckey produced the first 'modern' British medical work on hypnotism, many physicians eagerly anticipated enormous changes in medical thought and practice. Following on the heels of numerous physiological and pathological discoveries, to many physicians hypnotic therapy appeared to be the next stage in an all-encompassing scientific revolution in medicine. Taking tremendous care to distance modern scientific hypnotism from the dubious work of Mesmer and his followers, British medical supporters of hypnotism situated their experimental investigations in a scientific tradition that began more directly with their compatriot James Braid - the Manchester surgeon who coined the term in 1843. ${ }^{12}$ Unlike practitioners of mesmerism in the first half of the nineteenth century, Braid had viewed the patient's trance state as deriving from mental, rather than physical 'fluidic' causes. ${ }^{13}$ In Braid's view, the trance state was induced by the patient him/herself because it was based upon a willed decision to become entranced - a state which he likened to sleep - through the rigorous focus of the individual's full attention. In therapeutic practice, he held that the physician acted only as a guide for the hypnotised patient in helping to focus attention on producing relief from a wide variety of ailments. ${ }^{14}$

Looking back to Braid's important discoveries in the 1840s, hypnotism's supporters criticised the British medical profession for having failed to pursue hypnotic therapy after Braid's death in $1860 .{ }^{15}$ Following many decades of scientific resistance to the study of phenomena deemed psychological - as metaphysical and thus beyond the domain of physical laws - in the early 1890s, medical experimenters in hypnotism believed that they were living at a moment of far-reaching transformation in both therapeutic and

12 As practitioners of medical hypnotism worked to spread the news of their successes in treating a variety of ailments - including illnesses as diverse as neuralgia, asthma, hysteria, neurasthenia and alcoholism - this was the historical narrative that they related. Notable examples include C. Lloyd Tuckey, George Kingsbury, Scottish physician R.W. Felkin, J. Milne Bramwell, as well as D. Hack Tuke, editor of the Journal of Mental Science. The term 'hypnotism' was coined in James Braid, Neurypnology; or, The Rationale of Nervous Sleep, Considered in Relation with Animal Magnetism (London: Churchill, 1843).

${ }^{13}$ While Braid focused instead on the normal activities of the human mind, he did not produce a theory explaining how hypnotism worked: 'How these extraordinary effects are produced, it may be impossible absolutely to decide.' Braid, op. cit. (note 12), 176.

${ }^{14}$ Braid did not treat hypnotism as a panacea. In Neurypnology, he described his successes in using it to treat rheumatism, epilepsy, 'diseases of the skin', headaches, 'spasms', backache, as well as using it as an anaesthetic and analgesic during surgical operations. Braid, op. cit. (note 12), 176.

15 The view that hypnotism's history in Britain ended with Braid in 1860 until it was reintroduced in the latter half of the 1880s was shared by all British medical supporters of hypnotism in the 1890s. For example, Bramwell lamented the twenty-five year lull in the practice of medical hypnotism: 'Although the justness of Braid's views as to the subjective origin of mesmeric phenomena was generally admitted... the practice of hypnotism apparently ceased in England after Braid's death'. J. Milne Bramwell, Hypnotism: Its History, Practice, and Theory (London: Grant Richards, 1903), 29-30. George Kingsbury similarly noted that after Braid, 'The great body of the profession... do not seem to have taken kindly to hypnotism... Braid's work was speedily forgotten, and the therapeutic possibilities of hypnotism completely ignored'. Kingsbury proceeded to note that hypnotism's revival in France stemmed from Liébault's reading of Braid in the late 1850s. George Kingsbury, The Practice of Hypnotic Suggestion, Being an Elementary Handbook for the Use of the Medical Profession (Bristol: John Wright and Co., 1891), 11. 
psychological understanding. It was against this backdrop of expectant possibility that, from the mid-1880s, scientific interest in hypnotic research exploded across Europe. As the hypnotic work of the obscure privately practising French physician Ambroise Liébault was brought to public attention - following the discovery of his therapeutic successes by the chief physician at Nancy Hospital, Dr Hippolyte Bernheim, in 1882 - numerous physicians flocked to his practice in Nancy to witness the near-miraculous cures for themselves. ${ }^{16}$ Although Braid was credited with disputing the fluid materiality of the mesmeric trance, physicians agreed with Liébault and Bernheim's assessment that he had overlooked a very significant descriptive and explanatory detail - the effects of the physician's suggestions on the hypnotised patient.

Bernheim provided the theoretical elaboration for this new understanding of hypnotism in Suggestive Therapeutics in 1884, in which he defined hypnosis as nothing more than a heightened state of normal waking suggestibility. ${ }^{17}$ In his view, the hypnotic state arose through the physician's suggestion of hypnotic sleep, and enabled him more effectively to make therapeutic suggestions to the sick patient to cure him/herself. He held that hypnosis acted only as a means to make patients more receptive to their physicians' healthrestorative suggestions. Although Braid was frequently proclaimed by British physicians as the original pioneer in the development of 'modern hypnotism', Bernheim was in fact most responsible for the explosion of medical interest in the subject in Britain in the 1890 s - his theory of universal suggestibility provided the theoretical basis for British therapeutic hypnotism throughout the 1890s and 1900s. ${ }^{18}$ Following Bernheim, supporters of hypnotism held that it was the physician's suggestions, rather than the hypnotic state of 'sleep', that created the conditions for hypnotism's therapeutic effects.

Although medical interest in hypnotism in the early 1890s had been generated through the enthusiastic support of physicians in contact with medical research being done in France, interest in hypnotism was by no means exclusive to medical practitioners. British psychical researchers Edmund Gurney and Frederic W.H. Myers were the first individuals to engage in a systematic study of hypnotism in Britain (in the early 1880s). ${ }^{19}$

\footnotetext{
${ }^{16}$ Alan Gauld notes that the popular appeal among foreigners of hypnotic demonstrations in Nancy eclipsed the popularity of Charcot's demonstrations in Paris by the end of the 1880s. According to Gauld, 'the somewhat numerous foreign and other visitors to the Salpêtrière could hardly have been impressed by the demonstrations of transfer and other absurdities.... Foreign visitors interested in hypnotism began to show a tendency to visit Nancy [by 1887] as well as - and before long instead of - the Salpêtrière'. Among the visitors to Nancy from England were Arthur T. Myers, F.W.H. Myers, Edmund Gurney, C. Lloyd Tuckey, H. Rolleston, H. Wingfield and J. Milne Bramwell. Gauld, op. cit. (note 7), 336.

${ }^{17}$ Hippolyte Bernheim, De la suggestion et de ses applications à la thérapeutique (Paris: Doin, 1884). It was first translated in English as Suggestive Therapeutics in 1889. Bernheim argued that his work 'endeavoured to show that hypnotism does not really create a new condition: there is nothing in induced sleep which may not occur in the waking condition'; Hippolyte Bernheim, Suggestive Therapeutics: A Treatise on the Nature and Uses of Hypnotism, Christian A. Herter (trans.) (1889; reprint, New York: G.P. Putnam's Sons, 1895), 179.

18 As attested by reviews of his work in the British medical press, Bernheim was well respected within the British medical community throughout the 1880 s and 1890 s, and his positive reputation helped to bolster British medical hypnotists' claims. Exceptions to this general rule, such as $B M J$ editor Ernest Hart, tended to support Charcot in his campaign against the medical hypnotic work of Bernheim and supporters of the 'Nancy school'.

${ }^{19}$ Edmund Gurney and F.W.H. Myers were two of the founding members of Britain's Society for Psychical Research (SPR) in 1882. The SPR - among whose distinguished ranks were several Fellows of the Royal Society - was dedicated to discovering the natural laws governing what had traditionally been deemed 'supernatural' phenomena. The group focused its research on a wide variety of phenomena that had long been excluded from scientific study, chiefly including telepathy, hallucinations, spirit-mediumship, mesmerism and clairvoyance. Under Gurney's direction, the SPR's 'mesmerism committee' conducted extensive experimental investigations with hypnotic trance phenomena and 'post-hypnotic suggestion', and produced hundreds of pages of research
} 
While Gurney and Myers had observed and were impressed by the therapeutic uses of hypnotism on a visit to Nancy in 1885, they did not limit their own experimental research to hypnotism's therapeutic potential. For SPR investigators, hypnotism provided an invaluable point of entry into the innermost recesses of the human mind, and opened up the possibility for exploring its true nature and full capacities:

There is no reason why experiments should be confined to the hospital, or even to the 'psycho-physical laboratory'... it would be a grave retardation of science were it assumed that this strange metapsychosis was a medical curiosity alone. It is much more than this. It is the key which seems likeliest to unlock the mysteries of attention and memory; of sleep, dreams, and hallucination; of 'double consciousness' and of religious ecstasy... thus, perhaps, may [we] with most reason hope to lay the corner-stone of a valid experimental psychology, and to open up our deepest inlet to the inner man. ${ }^{20}$

Gurney and Myers held that the hypnotised individual exhibited an even stronger will and greater mental power than the waking self - as was seen, they argued, in the curative effects of hypnotic suggestions. They theorised that a secondary consciousness was active and dominant in the hypnotised subject while the primary (or waking) consciousness lay dormant. While the task of understanding this secondary consciousness was to preoccupy psychical researchers for the next fifty years, SPR investigations only infrequently directly intersected with British physicians' hypnotic investigations as their experimental work was more directly concerned with the underlying psychological explanation for hypnotic mental phenomena.

When hypnotism was introduced into British medical discussion in the 1890s, it was firmly embedded within a nexus of discussion and debate over the nature of the mind and its relationship to the body, and was not attached to one coherent set of ideas and practices. There were several interpretations of the hypnotic state and hypnotic susceptibility and many methods for employing hypnotism in medical practice. ${ }^{21}$ Further, the concept of hypnotic 'suggestion', to which British supporters of hypnotism appealed in explaining hypnotism's therapeutic effects, bore no consistent meaning in medical discussions. It was variously associated with the long-acknowledged contagious effects of a physician's attitude, ${ }^{22}$ while it also gestured towards a host of possible medical - and more broadly social - abuses. The absence of a definitive explanation for how suggestibility functioned, and uncertainty as to the precise nature of its role in everyday social life, brought a sense of urgency to medical discussions.

Although concern over the potentially 'dangerous' implications of individual suggestibility quickly became a central feature of discussions of hypnotism in the 1890s, the dominant tone of the lively discussions published in both the British Medical Journal and The Lancet in the months following Bramwell's demonstration was an optimistic openness to the possibility of hypnotism's value for medical practice. Even the staunchest

reports in the 1880s. In the first half of the 1880s, before hypnotism had once again come to the attention of British physicians, Gurney was arguably the most important British researcher into the nature of hypnotic phenomena since Braid; see Gauld, op. cit. (note 7), 391-2.

${ }^{20}$ Edmund Gurney and Frederic W.H. Myers, 'Some Higher Aspects of Mesmerism', Proceedings of the Society for Psychical Research, 3 (1885), 401-23: 422 (original emphasis).

${ }^{21}$ In his handbook on hypnotism, George Kingsbury listed no fewer than fourteen methods for inducing hypnotism. Kingsbury, op. cit. (note 15), 20-8.

22 The long-held medical wisdom that 'to inspire a patient with hope and confidence is as valuable a stimulus towards recovery as half the drugs in the Pharmacopeia', was so firmly embedded in the received medical view of therapy that many physicians believed that 'suggestive therapeutics' signified nothing more complex than the legendary health-restorative effects of a physician's cheerful attitude. Sir Francis Cruise, introduction to Tuckey, op. cit. (note 4), xxii. 
opponents to hypnotism supported the BMA's decision to pursue the matter more thoroughly. Although Dr Norman Kerr proclaimed that hypnotism created a potentially disastrous affective bond between the hypnotist and the hypnotised - which he described in vivid terms as a "jelly-fish slavery without mental or moral backbone" ${ }^{23}$ - he cast his vote in favour of further investigation. As a result, at the conclusion of the annual meeting of the BMA's psychological section in 1890, when the BMA's president, Sir Willoughby Francis Wade, put to the vote the formation of 'a committee of medical men with the object of endeavouring to ascertain the true nature of its phenomena, and the propriety, or otherwise, and the value of its use in the treatment of disease,' it was 'carried unanimously'. ${ }^{24}$ Witnessing physicians' enthusiasm in 1890 at the prospect of a new therapeutic revolution in medicine, few present at this gathering would have predicted hypnotism's status of disrepute by 1898. 'Suggestive therapeutics' appeared for many to be the logical outcome of another revolution in scientific discovery.

\section{Defining the Hypnotically Susceptible: The Suggestible Subject and the Problems of Influence}

The question of who was susceptible to hypnosis was a crucial preoccupation from the start. In light of critics' claims that only 'men and women of a low nervous and intellectual type $^{25}$ could be hypnotised, determining whether the capacity to be hypnotised was symptomatic of health or illness was uppermost on the agendas of both physicians and SPR investigators. British physicians' accounts of trips to Nancy and Paris emphasised that the choice of subjects for hypnotic experimentation both reflected and helped shape the scientist's beliefs about hypnotic susceptibility. Moreover, the choice of experimental subjects also had a significant impact on the phenomena witnessed and then associated with the hypnotic state. British physicians never failed to mention their pleasant surprise at seeing how remarkably differently hypnotised patients appeared and behaved in Nancy in comparison to the hysterical patients in Paris at the Salpêtrière hospital for women. Medical psychologist George Robertson noted that in contrast to the carefully orchestrated theatrics of Jean-Martin Charcot's hysteric hypnotic subjects - who, guided by his commands, expressed from one moment to the next trance-like lethargy and effusive emotion $^{26}$ - the effects of hypnosis were so subtle at the hospital in Nancy that it was 'a very difficult thing to tell by any external sign when hypnosis had occurred... as the patients look[ed] so natural and [were] so conscious of all that goes on around' ${ }^{27}$ The differences between the phenomena exhibited by Charcot's and Bernheim's subjects were vast, and medical visitors unfailingly noted 'the quiet, ordinary, everyday tone' of Liébault's medical practice in 'marked contrast to the picture drawn by [Salpêtrière physicians] Binet and Féré of the morbid excitement shown at the Salpêtrière': ${ }^{28}$

\footnotetext{
${ }^{23}$ Norman Kerr, 'A Discussion on Hypnotism and Therapeutics', British Medical Journal, 2, 1547 (23 August 1890), 442-9: 443.

24 Ibid., 446.

${ }^{25}$ Henry Blandy, 'Hypnotism as an Anaesthetic', The Lancet, 135, 3478 (26 April 1890), 937-8: 938.

${ }^{26}$ George M. Robertson, 'Hypnotism at Paris and Nancy, Notes of a Visit', Journal of Mental Science, 38, 163 (October 1892), 494-531: 505. Robertson described in great detail how Charcot's hypnotised hysterical patients could express more than one emotional state at once: 'I had before me a person angry with one side of the face and laughing with the other. The appearance was very odd and peculiar, and the effect was rather confusing'.

27 Ibid., 512.

${ }^{28}$ Bramwell, op. cit. (note 15), 31-2.
} 
The patients told to go to sleep apparently fell at once into a quiet slumber, then received their dose of curative suggestions, and when told to awake, either walked quietly away or sat for a little to chat with their friends... Liébault took especial pains to explain to his patients that he neither exercised nor possessed any mysterious power, and that all he did was simple and capable of scientific explanation. ${ }^{29}$

The calm 'everyday tone' of Nancy experiments with hypnosis was held up by British supporters of hypnotism as proof that when induced by a trustworthy adherent of the 'Nancy school', the hypnotic state was simply a heightened - and, at worst, innocently comical - version of conscious waking life.

Hypnotism's most ardent supporters constructed their arguments attesting to its therapeutic benefits around their beliefs about the non-pathological nature of hypnotic susceptibility. Determining who was susceptible to hypnosis and, perhaps more importantly, who was not was crucial to persuading their scientific audiences that it was a necessary addition to physicians' therapeutic canon. Tuckey argued adamantly against the perception that 'neurotic' people were the most easily hypnotised: 'Private soldiers and agricultural labourers... are "good subjects" for hypnotism.... Strong muscular and intelligent men and women are, in my experience, the best subjects for hypnotism. 30 Bramwell similarly noted that 'many of [his] most successful cases were strong healthy males, who were easily hypnotised for operative and experimental purposes'. ${ }^{31}$ Explicitly challenging the assumptions prevalent among hypnotism's detractors, Bramwell argued that hysterical women were among the most difficult to hypnotise while healthy young men were almost uniformly susceptible: 'the intelligent man with the well-balanced brain is more or less easily influenced'. ${ }^{32}$ The picture which hypnotism's supporters generally presented of the hypnotisable subject was male, intelligent, and in good physical and mental health.

In adopting Bernheim's theory of universal suggestibility as the explanatory basis for the healthy nature of hypnotic susceptibility, British supporters of hypnotism were confronted with a new conception of social life. Describing hypnotism as a 'normal' state of heightened suggestibility, and thereby revealing human beings to be highly receptive to the suggestive power of the outside world, Bernheim radically altered how the human being's relationship to the external world was conceived. Formulated in the immediate wake of universal enfranchisement in France, Bernheim's theory of suggestibility posed a serious challenge to the notion that individuals could make autonomous rational and moral decisions. Hypnotic treatment via suggestion implied that the patient suspended their 'independence of thought' and believed everything that the physician communicated without question. Noting how extreme was the deeply hypnotised patient's level of suggestibility, one medical hypnotist, Dr George Kingsbury, described how 'the subject will imitate every gesture of the operator' in the manner of a puppet. ${ }^{33} B M J$ editor Ernest Hart pointed to the dangers of hypnotism in maintaining that the hypnotised subject became a 'marvellous machine, astonishingly, blindly, actively obedient to your wildest orders or most bizarre suggestions'. ${ }^{34}$ Both critics and supporters of hypnotism invoked the vivid language of automatons, 'instruments' and 'machines' in their descriptions of the

${ }^{29}$ Bramwell, op. cit. (note 15), 31-2.

${ }^{30}$ Tuckey, op. cit. (note 4), 66-7.

31 Bramwell, op. cit. (note 15), 63.

32 Bramwell, op. cit. (note 15), 63.

33 Kingsbury, op. cit. (note 15), 22.

${ }^{34}$ Ernest Hart, 'Hypnotism, Animal Magnetism, and Hysteria', British Medical Journal, 2, 1666 (3 December 1892), 1215-20: 1219. 
profoundly suggestible hypnotised subject. Resolving the dilemma of whether physicians should be allowed to exert overt control over their patients was of central importance in considerations of whether hypnotism should be made an acceptable medical practice.

With the potentially immoral, and even dangerous, consequences of heightened suggestibility and hypnotic 'rapport' noted at an early point in medical discussions of hypnotism, the doctor-patient relationship was subjected to intense scrutiny regarding issues of trust and social propriety. The possibility of illicit sexual relations between physicians and their female patients pervaded discussions of hypnotism in the 1890s. Both supporters and detractors of hypnotism regularly invoked lurid criminal scenes involving hypnotised women and morally depraved hypnotists to support their calls for strict legislation limiting hypnotic practice to qualified medical practitioners. ${ }^{35}$ Popular warnings in the medical literature involved hypnotised women impregnated against their will, as well as otherwise moral women forced through suggestion to commit crimes on behalf of their hypnotist.

Not only did the prospect of hypnotic therapy present new possibilities for criminal abuse, the theory of hypnotic suggestibility also called into question the much-prized notion of innate moral consciousness. Hypnotism's supporters lacked a systematic explanation of the hypnotic state that preserved both the hypnotized subject's autonomy and moral conscience. ${ }^{36}$ If universal suggestibility were to be accepted as a fact of human life, then moral values would lose their cherished status as 'natural', and be reduced to illusory, and eminently vulnerable, socially prescribed concepts. John Milne Bramwell criticised Bernheim's challenge to innate morality, claiming that it was not only dangerous, but illogical:

when one considers that Bernheim... boldly asserts that there is nothing in hypnotism but the name; that it does not create a new condition, and that hypnotic acts are only exaggerated normal ones... [yet claims that] the moral state in hypnosis differs widely from the normal... [this is an] obvious contradiction to his own conception of hypnotism. ${ }^{37}$

Bramwell condemned hypnotism's supporters in Britain for failing to resolve the troubling contradiction in Bernheim's view of the hypnotised subject's incapacity for moral awareness.

Although there was much enthusiasm for hypnotic research in the 1890 s, the porousness of mental boundaries implied in Bernheim's theory of universal suggestibility opened up a host of frightening possibilities. As hypnotism in late nineteenth-century medical practice intrinsically involved relationships of potential influence between individuals of differing social backgrounds, the complex set of tensions at the heart of modern social relationships exploded onto the pages of medical journals. Doctors committed to promoting hypnotism's

\footnotetext{
35 Concerns that certain devious women might also use hypnotism to further their ill-intentioned 'designs' against their doctors, or to force unsuspecting men into marriage, appeared in medical discussions of hypnotism alongside expressed fears that women might be made victims of a hypnotist's criminal intentions. A case in which a young woman probably used hypnotism to force a man to leave his wife and marry her was reported in the $B M J$ on 15 March 1893: 655: 'Therapeutically the value of hypnotism is obviously but slight and occasional; its moral and social perils are certain and serious'. Warnings that physicians were equally in danger as 'false charges' could be brought forth by 'designing female[s]' were also common. As a precautionary measure, Kingsbury prescribed certain rules of practice according to the patient's sex - if the patient was female, then a 'respectable' witness should always be present (if unmarried, her mother, and if married, her husband). Kingsbury, op. cit. (note 15), 122.

36 As Ruth Harris points out, Bernheim's theory of suggestibility was interpreted by French medico-legal experts as in many cases revealing the instability of social and moral absolutes. Harris, op. cit. (note 10), 181.

37 J. Milne Bramwell, 'On the Evolution of Hypnotic Theory', Brain, 19, 4 (1896), 459-568: 499.
} 
remarkable effects in restoring health were faced with the difficult task of convincing their audiences that its therapeutic benefits outweighed its potentially damaging costs to an increasingly tenuous social order.

\section{Determining the Limits of Suggestibility: Medicine, the Public, and the Challenge to Social Order}

Amidst debate over the potentially dangerous and amoral consequences of the hypnotic heightening of individual suggestibility, physicians unanimously agreed on one issue: public demonstrations of hypnotism needed to be stopped. Medical journals throughout the 1890 s were replete with warnings about the dangers of hypnotic demonstrations before unscientific audiences. In identifying public demonstrations of hypnotism as a danger, both medical supporters and critics of hypnotism commonly established clear distinctions between scientific and unscientific audiences. At the BMA's annual meeting in 1891, the physicians present unanimously agreed that 'the public exhibition before unscientific and miscellaneous audiences, and for the purposes of gain or amusement, of the phenomena of hypnotism' should be banned, as they were 'antagonistic to public morality'. ${ }^{38}$ In emphasising the 'unscientific and miscellaneous' status of the audiences - in addition to the unethical agenda of stage hypnotists who were motivated by a desire for personal profit - physicians were particularly concerned about audience members' suggestibility as manifested in an inability to detect the fiction involved in hypnotic performance, and confuse entertainment with reality. Physicians worried that the public's suggestibility in combination with the deceptions of stage performers would lead to a general degradation of people's minds, resulting not only from witnessing a fiction masquerading as truth, but in actively desiring this kind of performance and deriving pleasure from the possibility of its imagined reality.

Stressing the dangers of public performers' gross misrepresentation of scientific facts in their opposition to stage hypnotism, medical supporters of hypnotism emphasised that their own exhibitions were concerned purely with the disinterested demonstration of genuine phenomena. As the dissemination of medical knowledge about hypnotism was greatly dependent upon hypnotic demonstrations, supporters needed to assert their ability to detect deceit successfully. In a brief description of a series of medical demonstrations given in the 1880s, Scottish physician R.W. Felkin was careful to note that scientific audiences were sufficiently sceptical to recognise the difference between genuine and fraudulent phenomena: 'when hypnotic phenomena are witnessed in a scientific spirit by competent observers, fraud, or even unconscious deception, is not likely to pass muster' ${ }^{39}$ Felkin's insistence that scientific audiences possessed the observational skills necessary to avoid being fooled by 'trained' hypnotic subjects was premised upon the view that non-scientific (and uncritical) audiences lacked the necessary intellectual training to be so discerning. Participants in the hypnotism debate thus distanced themselves from the natural suggestibility of uneducated audiences - which they elided with concerns about public morality - through an emphasis upon the mental rigour of a scientific education. ${ }^{40}$ The explicitly articulated assumption that university education countered the potential for succumbing to false suggestions enabled physicians to establish clear distinctions in levels of suggestibility between educated and uneducated social classes.

38 British Medical Journal, 7 February 1891: 321.

${ }^{39}$ R.W. Felkin, Hypnotism or Psycho-Therapeutics (Edinburgh: Pentland, 1890), 7.

${ }^{40}$ Ibid., 7. 
Physicians' deep reservations about the potential consequences of the suggestible nature of 'unscientific and miscellaneous audiences' was rooted in a general mistrust of those large sections of the British population that had only in the last few decades become increasingly literate, educated at a primary school level, and enfranchised. ${ }^{41}$ Bramwell singled out the negative effects of a mass press that thrived on the propagation of sensational, and often inaccurate, information as an obstacle to physicians' hypnotic research since 'nearly every one ha[d] read, and been more or less influenced by, various unfounded newspaper stories regarding the dangers of hypnotism'. ${ }^{42}$ As 'the public generally ha[d] accepted the misleading statement that hypnosis is characterised by unconscious and suspended volition', patients 'under the influence of these ideas' could not be hypnotised. ${ }^{43}$ In order to make this point clear, he described his successes with hypnotism in the late 1880s and early 1890s on patients in Goole, in East Yorkshire, where 'hypnotism had not been discussed in newspaper and magazine articles' ${ }^{44}$ In Bramwell's view, the effect of the media on suggestible minds was so remarkable that it interfered with patients' ability to be hypnotised.

How physicians viewed the 'public' was strongly shaped by their interests as members of the expanding middle class. As defenders of middle-class values, physicians' vision of a healthy society coincided with bourgeois assumptions about the immorality of the lower classes. The unintended consequences of modern 'progress', and some of its most frequently discussed threats in the late nineteenth century, were perceived increases in urban criminality, insanity, alcoholism and venereal disease - all understood as originating and proliferating among the lower classes, and increasingly explained in the medical language of degeneration. As a key marker of this medicalisation of social problems, physicians conflated moral anxieties about the lifestyle of the less educated 'masses' with concerns about public health and welfare - as well as 'public morality'. In a similar spirit, participants in the hypnotism debate elided concerns about the implications of individual suggestibility for doctor-patient relations with the potential influence which public performers, political orators, ${ }^{45}$ and sensational writers had on their presumably uneducated lower-class audiences. Throughout the 1890s, suggestibility was aligned with the more troubling signs of Britain's seemingly inexorable democratisation.

Although universal suggestibility signified a threat to social order, and the possible need for tighter legal controls over what the public saw, read and heard, it was also interpreted by a number of physicians as having potentially beneficial uses, not simply in curing unhealthy patients, but in reforming deviant behaviour. The possibility that the public, or at least its most undesirable members, could be molded through hypnosis to conform to late nineteenth-century behavioral norms was explored by many physicians alongside therapeutic research. In 1901, American physician R. Osgood Mason produced a work

\footnotetext{
41 The Third Reform Act of 1884 increased the franchise to include 60 per cent of the adult male population (all men who owned land valued at $£ 10$, or paid an annual rent of at least $£ 10$, received the vote). For the first time, working-class voters had the potential to make up the majority of the electorate. Although Britain was by no means a democratic society by the end of the nineteenth century, the feeling among much of the middleand upper-class population was that full-scale democratisation was inevitable. See Harold Perkin, The Rise of Professional Society: England Since 1880 (New York: Routledge, 1989).

42 Bramwell, op. cit. (note 15), 65.

43 Bramwell, op. cit. (note 15), 66.

${ }^{44}$ Bramwell, op. cit. (note 15), 72.

${ }^{45}$ For instance, one anonymous contributor to the $B M J$ pointed to the 'hypnotizing effect which a sophistical orator may have on the great mass of the people'. 'Hypnotism and Electioneering', British Medical Journal, 1, 2058 (9 June 1900), 1426-7: 1426.
} 
devoted entirely to the subject of hypnotism as a mode of 'education'. He proclaimed that an 'educational field' of hypnotic investigation was 'beginning to be opened up' alongside 'the therapeutic' and 'the psychological' fields. Mason described this 'educational field' as founded upon 'the influence which may be exerted by hypnotism upon the development and improvement of the mind'. ${ }^{46}$ He was optimistic that this new educational field,

may yet prove of greater interest and utility than either of the others... when one views the number of children brought into the world with imperfect mental organizations and vicious tendencies, and sees how little impression in general is made upon them by the ordinary and even the special processes of education. ${ }^{47}$

Although Mason claimed that this new area of investigation was only in its early phases of development, British physicians had been using hypnotism to cure a variety of moral defects - kleptomania, 'perverted sex', nail biting and even lies - for a decade. ${ }^{48}$

The promises which individual suggestibility held out as a locus of moral persuasion and site of social reform were significant, however the absence of clear understanding concerning its precise limits made any firm distinction between hypnotist and subject, doctor and patient, scientific audience and the public difficult to establish. The nearimpossibility of definitively determining the direction of influence and the precise nature of suggestions' mysterious operations were subtle, but crucial, issues that hypnotism's medical detractors brought to the discussion. If suggestibility was universal, as hypnotism's supporters claimed, then where did it stop? How could physicians be certain that they were not on the receiving end of suggestions when they experimented with hypnotised patients, and that the hypnotic phenomena witnessed were not being deliberately, or even unconsciously, performed? In response to the problem of experimental subjects' deception, described by psychical researchers as the potential for 'mal-observation', ${ }^{49}$ physicians could do nothing more than appeal to their scientific training as a guarantee against mistaking a subject's conscious (or unconscious) performance for reality.

In his condemnation of therapeutic hypnotism, Ernest Hart appealed to the unknown limits of suggestibility in arguing against physicians' ability to perceive cases of fraud. In a sensational exposé of British medical researchers' work with a trained hypnotic subject, Hart described how he had paid a professional hypnotic subject to perform for a group of prominent medical men - including Bramwell. Believing the 'trained subject' - referred to only as 'L.' - to be genuine, Hart reported that the medical men were duped because of their desire to see real hypnotic phenomena. Noting the particularly 'histrionic' quality of L.'s 'over-acted' performance, Hart questioned the integrity of the judgement of the

${ }^{46}$ R. Osgood Mason, Hypnotism and Suggestion in Therapeutics, Education, and Reform (New York: Henry Holt and Co., 1901), 131.

47 Ibid., 131.

48 These vices were listed in Bramwell's Hypnotism: Its History, Practice, and Theory, alongside the promise that hypnotism could be used to reform the behaviour of 'vicious and degenerate children'. Bramwell, op. cit. (note 15), 177-267. In his section on hypnotism's therapeutic uses, Tuckey similarly includes 'moral breakdown', 'mania for washing', 'kleptomania', and 'morbid sexuality'. Tuckey, op. cit. (note 4), 322-67. The use of hypnotism in German sexology is another noteworthy example of its use as a moral corrective and means for 'educating' therapeutic subjects. Richard von Krafft-Ebing, Albert von Schrenck-Notzing, and Albert Moll all made extensive use of hypnotism as a means for 'curing' homosexuality.

${ }^{49}$ Psychical researchers devoted significant attention to developing methods for detecting fraud. Articles on the avoidance of 'mal-observation' were published consistently from the early 1880s through to the early twentieth century. 
medical men, and speculated that if such well-respected men of science could be fooled, then very little could be expected of the lay public:

if such things be possible in the green wood of an intellect originally trained to scientific observation, what is likely to happen in the dry sticks and shakings of half educated, wholly uncritical, and superstitious minds ready to take fire at the slightest spark of the mysterious? $?^{50}$

Challenging distinctions presumed to separate scientific demonstrations from public entertainment, Hart argued that medical demonstrations of hypnotism held no scientific worth other than their 'foolometric value'. 51

In his exposure of the physicians' credulity, Hart inadvertently presented a critique that could have been levelled at a wide variety of forms of scientific inquiry: 'Men are easily induced to see what they are anxious to see, and even the dry light of science does not always keep its votaries out of this pitfall. "Suggestion" often acts more powerfully on the operator than on the subject. ${ }^{52}$ Invoking the power of suggestion to explain how medical hypnotists could fall prey to illusion during 'scientific' investigations of hypnotism, Hart turned the problem of suggestibility onto professional medical men. He also further complicated the already complex relationship between hypnotist and hypnotised by concluding that hypnotic subjects were 'not only born, but... made'. ${ }^{3}$ Arguing that the phenomena of hypnotism were only at best partially genuine, he claimed that physicians unwittingly trained their hypnotic subjects, moulding them to perform the symptoms that they were 'anxious to see'. In support of his claim, he pointed to Jean-Martin Charcot's peculiar hysterical hypnotic subjects, whose highly theatrical 'symptoms' exhibited under hypnosis could not be found anywhere outside the sphere of the French neurologist's direct influence. ${ }^{54}$

Hart's mistrust of hypnotic subjects, in combination with audiences' expectations of a specific kind of trance performance, was in line with relatively common concerns about the problematic nature of normal waking suggestibility. His emphasis on medical investigators' unreliability due to their suggestible natures was consistent with the interpretation taken up by crowd psychologists at the turn of the century. In his highly influential 1895 work on crowd psychology, Gustave Le Bon argued that the even the most rational scientists could fall prey to an unconsciously derived suggestibility when working in a group. Premised upon his foundational theory that individuals in groups lose their critical abilities as a direct result of an affective and contagious suggestibility, ${ }^{55}$ Le Bon argued that during scientific studies of phenomena associated with spiritualism, scientists became blinded by a collective suggestibility generated through group association. As a result, they often witnessed things that had not occurred in any real, or objective, sense: 'The faculty of observation and the critical spirit possessed by each of them individually

\footnotetext{
${ }^{50}$ Ernest Hart, 'The Eternal Gullible: The Confessions of a Professional Hypnotist', The Century Illustrated Magazine, 48 (1894), 833-9: 833.

51 Ibid., 839.

52 Ibid., 839.

53 Ibid., 834.

${ }^{54}$ Ernest Hart, Hypnotism, Mesmerism, and the New Witchcraft (London: Smith, Elder, and Co., 1893), 135.

55 Gustave Le Bon, The Crowd: A Study of the Popular Mind (1896; reprint, London: Berg, 1947), 10-1, first published in France in 1895, and translated into English in 1896. Le Bon described the most important cause of crowd behaviour as: 'that suggestibility of which, moreover, the contagion mentioned above is neither more nor less than an effect... The most careful observations seem to prove that an individual immersed for some length of time in a crowd in action soon finds himself... in a special state, which most resembles the state of fascination in which the hypnotized individual finds himself in the hands of the hypnotizer'.
} 
at once disappears.... Here, as always, we have the power of the hypnotiser over the hypnotised. 56

Le Bon's theory was widely known in Britain by the end of the nineteenth century, and, in 1907, Wilfred Trotter, an English surgeon and budding social psychologist, acknowledged Le Bon's interpretation of suggestibility as a predecessor to his own, more up-to-date biological version. ${ }^{57}$ Appealing to the concept of suggestibility to explain not simply crowd behaviour but all human behaviour, Trotter argued that suggestibility was a primary attribute of the 'herd instinct', and a foundation of all human social life:

If the biological explanation of suggestibility here set forth be accepted, the latter must necessarily be a normal quality of the human mind.... Man is not, therefore, suggestible by fits and starts, not merely in panics and in mobs, under hypnosis, and so forth, but always, everywhere, and under any circumstances... variations [in suggestibility] are due to the differing extent to which suggestions are identified with the voice of the herd. ${ }^{58}$

Trotter proclaimed human beings to be fundamentally social - they were driven by an instinctive will to sociability and desire for social acceptance. As a result, the suggestions of the individual's social group (or 'herd') determined how they behaved. Following from this initial premise, Trotter argued that men of science were not naturally compelled to approach the world rationally, but were guided through the suggestions of their community - their teachers and colleagues - to adhere as much as possible to the rigorous strictures of reason in their work. 59

By the first decade of the twentieth century the concept of suggestibility had been appealed to in explanations of a wide variety of social phenomena that involved individuals at every level of British society. Fitting scientists into a grand social psychological theory of suggestibility was in many ways to take Bernheim's initial concept - as an explanation for the effects of hypnotism - to its full and logical conclusion. From initially signifying the 'slightly increased influence' of the physician over the patient in the late $1880 \mathrm{~s},{ }^{60}$ its theoretical consequences expanded over the course of the $1890 \mathrm{~s}$ and early 1900s as it was increasingly invoked as a means of explaining a wide variety of aspects of social life. By the early twentieth century, suggestibility had tremendous explanatory power for understanding social behaviour - from the effects of newspapers on readers and public entertainment on audiences, to politicians' hold over crowds, to the discoveries made by small groups of scientists. The appeal of suggestibility within the newly developing field of social psychology at the turn of the century centered upon the view that traditional hierarchical society was quickly dissolving into modern 'mass' society. While suggestibility was a cause for concern, and signified an obstacle to both patients' and physicians' capacity for rational responsible behaviour, Trotter attempted to resolve its potentially negative consequences through practical solutions provided by his biologically derived social psychology. The suggestions of the 'herd' could work in

\footnotetext{
56 Ibid., 25-6.

${ }^{57}$ I use the term 'social psychology' to describe theories of crowd, mass and other 'group' behaviours and psychological motivations.

58 Wilfred Trotter, Instincts of the Herd in Peace and War (1919; reprint, New York: MacMillan Co., 1947), 34. This particular chapter was first published as 'Herd Instinct and its Bearing on the Psychology of Civilised Man', The Sociological Review, 1, 3 (1908), 227-48.

${ }^{59}$ Ibid., 40: 'to the student of biology the principles of Darwinism may acquire the force of herd suggestion through being held by the class which he most respects, is most in contact with and the class which has, therefore, acquired suggestionising power with him'.

60 C. Lloyd Tuckey, 'The New Hypnotism: A Reply', Contemporary Review, 63 (1893), 416-9: 418.
} 
favour of truth: as 'the suggestibility of man does not necessarily or always act against the advancement of knowledge', traditional ideals of rationality and progress did not need to be abandoned. ${ }^{61}$ Trotter urged that it was the task of scientists to make scientific modes of thought and behaviour socially desirable, and so seemingly powerful that everyone would be compelled to follow.

By 1907, when Trotter formulated his optimistic solution to the apparent chaos of human suggestibility, discussions of hypnotism in medical journals had been in retreat for several years. When Tuckey summed up the recent developments in hypnotic research in the preface to the fifth edition of his textbook on hypnotism in 1907, he required only one sentence: 'The seven years which have elapsed since the publication of the fourth edition of this work have not been marked by any striking development of hypnotic theory or practice.' ${ }^{62}$ By 1900 , neither the dangerous implications of suggestibility nor the precise nature of hypnotism's social effects had been resolved by hypnotism's supporters. Physicians could not even establish consensus over the exact meaning and implications of 'suggestive therapeutics'. Riven by internal disagreement, supporters of hypnotism increasingly turned their focus away from public medical debate to the safety and seclusion of private investigation. ${ }^{63}$

\section{The Medical Rejection of Hypnotism and the Triumph of Suggestible Subjectivity}

Although the theory of suggestibility was riddled with ambiguities from the moment that it was conceived, hypnotism's retreat from medical discussion was not a foregone conclusion in the 1890s. The Nancy conception of universal suggestibility was not the only explanation for hypnotism available to British physicians. Psychical researcher Frederic W.H. Myers' theory of the 'subliminal self', which explained hypnotic susceptibility without espousing suggestibility, entered into public discussion in the 1890s and 1900s. ${ }^{64}$ Despite the fact that Myers was not a physician, nor an academically trained scientist, he was invited to the BMA's annual meeting in the autumn of 1898 to present a paper outlining his theory of hypnotic consciousness. The months following his psychologically complex address were marked by a noticeable silence in response to his approach to the potential problem of suggestibility. As we shall see, the absence of medical interest in Myers' revolutionary theoretical paradigm for understanding mental life signalled the end of the hypnotism debate. The medical receptiveness to hypnotism's open-ended possibilities that marked the early 1890 s had been closed down by 1898 . The problems raised by the theory of universal suggestibility could not be resolved within late-Victorian

61 Trotter, op. cit. (note 58), 40.

62 Tuckey, op. cit. (note 4), vii.

63 This is not meant to imply that all of hypnotism's supporters in the 1890 s remained committed to hypnotic investigation. George Kingsbury, for example, never wrote another word on the subject. However, hypnotism's most vocal early advocates, Charles Lloyd Tuckey and J. Milne Bramwell, published important books on the subject during the first decade of the twentieth century.

${ }^{64}$ Myers' theory of consciousness was, in large measure, derived from the SPR's investigations of the hypnotic trance state and post-hypnotic suggestion that were headed by Edmund Gurney between 1882 and 1888 (and by Myers following Gurney's death in 1888). Myers' experience of hypnotic mental phenomena was much more extensive than that of most British physicians by 1898, qualifying him as an expert in the area. Recent studies have revealed the prevalence and, to some extent, popularity of Myers' theories of consciousness in late Victorian and Edwardian Britain. See Roger Luckhurst, The Invention of Telepathy, 1870-1901 (Oxford: Oxford University Press, 2002); Thurschwell, op. cit. (note 9). 
physicians' traditional epistemological framework, and as a result hypnotism was pushed off the public medical agenda.

As Myers explained in his 1898 paper, the hypnotist's suggestions did not act in the place of the subject's will, or contrary to the subject's desires, but 'set going some intelligent organic faculty in the man which laid dormant till that moment, and which proves more effectual for healing than the man's conscious will'. ${ }^{65}$ Shifting the focal point of theoretical explanation from the influence of the hypnotist's suggestions to the hypnotised individual's 'self-suggestion', Myers argued that the hypnotist served to unlock 'some fountain of energy which was latent within the man's own being'. ${ }^{66}$ Myers explained this crucial, but psychologically complex, point to the physicians present using the metaphor of a factory to describe the mind, and the factory proprietor to describe the waking self:

In waking consciousness I am like the proprietor of a factory whose machinery I do not understand. My foreman - my subliminal self - weaves for me so many yards of broadcloth per diem (my ordinary vital processes) as a matter of course. If I want any pattern more complex, I have to shout orders in the din of the factory, where only two or three inferior workmen hear me, and shift their looms in a small and scattered way. Such are the confined and capricious results of the first, the more familiar stages of hypnotic suggestion. At certain intervals, indeed, the foreman stops most of the looms, and uses the freed power to stoke the engine and to oil the machinery. This, in my metaphor, is sleep, and it will be an effective hypnotic trance if I can get the foreman to stop still more of the looms, come out of his private room, and attend to my orders - my self-suggestions - for their repair and rearrangement. ${ }^{67}$

Stemming from his belief that the hypnotised individual remained under the control of their secondary consciousness, he argued that subjects choose to follow suggestions and do not passively obey. Further, Myers argued that hypnotised subjects could not be forced to commit crimes - that they would not otherwise commit - because hypnotised individuals always acted in accordance with their own self-suggestions - and moral conscience.

Myers' approach to hypnotic consciousness provided the basis for a very different, and more hopeful, view of the hypnotised subject. Opposing the image of the automaton - a popular metaphor to describe hypnosis for participants on both sides of the debate - adherents of Myers' theory of the 'subliminal self' refuted the notion that there was any lapse in the hypnotised individual's sense of social and moral propriety. ${ }^{68}$ Describing his experiences with hypnotism in 1896, Bramwell related how three young female patients lost neither the ability to reason, moral sensibility, nor sense of social propriety while in a hypnotic state. 'Miss C., aged 19, an uneducated girl' 69 would not, while hypnotised, allow him to extract a decaying tooth until he had carefully and rationally explained the medical reasons for his intervention. 'Miss F., aged 19, in good health, intelligent, and well-educated', would not carry out the post-hypnotic suggestion to 'go to the sideboard in [Bramwell's] room, pour out a glass of water, and drink it' ${ }^{70}$ When her mother was

${ }^{65}$ F.W.H. Myers, 'The British Medical Association and Hypnotism: The Psychology of Hypnotism', Proceedings of the Society for Psychical Research, 14 (1898), 100-8: 107.

66 Ibid., 107.

${ }^{67}$ Ibid., 107-8.

68 J.P. Williams has also noted the late nineteenth-century conflict between medical and SPR understanding of the hypnotic trance state. Whereas many Victorian physicians viewed the trance state as a sign of mental pathology, the SPR instead tended to look to it as a potentially hopeful indication of higher evolutionary psychical attributes and capacities. Williams, op. cit. (note 9).

${ }^{69}$ Bramwell, op. cit. (note 37), 487.

${ }^{70}$ Bramwell, op. cit. (note 37), 489. 
later asked why she had refused, she explained 'that she did not know [Bramwell] well enough to help herself to a glass of water in [his] house without being asked'. ${ }^{71}$ When he asked 'Miss E.... maid to one of [his] patients', while hypnotised to reveal the private details of an event involving her employer, 'she absolutely refused to say a word on the subject'. ${ }^{72}$ Bramwell, following Myers, hypothesised that the hypnotised individual was animated by a secondary, and more powerful, consciousness:

If I were asked in one word to describe the difference between the hypnotised and the non-hypnotised subject, I should say that it consisted in the superiority of the former over the latter in his having reached a far-reaching power over his own organism, which the other does not share. This view of the hypnotic state is not a novel one, and has already been ably described by Mr Frederic Myers. ${ }^{73}$

Not only did the hypnotised individual remain in full control of her surroundings but also self-control was more resolute while she was hypnotised.

In following Myers' approach to hypnotism, Bramwell was a notable and vocal exception among British physicians. Medical professionals' responses to Myers' paper in 1898 were generally unsympathetic, and ranged from dismissive to explicitly hostile. One contributor to the $B M J$ rejected Myers' theory as unsubstantiated and ultimately unhelpful in understanding hypnotism:

It is not clear that anything has been gained by the introduction of the term 'subliminal consciousness'.... We are not persuaded that Mr Myers has given us proof that hypnotism has the power to arouse faculties which are dormant in the normal condition. ${ }^{74}$

According to this anonymous contributor, Myers was inconsistent in claiming that the hypnotised individual responded to suggestions made for curative purposes, but did not respond to criminal orders:

The exponents of the hypnotic faith cannot have it both ways; they cannot urge that hypnotism is effective and yet not effective as may suit the argument of the moment... There is no hypnosis, in the sense indicated by Dr Bramwell, without suggestion; and we deprecate its use while it holds out any inducement to a man, however feeble, to resign his responsibility and become the passive agent of another however well-intentioned. ${ }^{75}$

Suggestion, and its attendant dangers, remained the dominant issue under discussion. Myers' theory, which proclaimed all suggestions as self-suggestions, was swiftly dismissed as another (and incorrect) version of mental pathology: 'It would appear that, using the example cited by Mr Myers... we might more correctly and more suggestively speak of the "fringes of consciousness".,76 Hysteria and 'mania' were then cited as exemplary conditions stemming from the 'fringes of consciousness'.

Although many physicians were troubled by the possible criminal and amoral implications of the suggestible hypnotised subject, almost none rejected this version of the self in favour of Myers' 'subliminal self', despite the fact that it preserved innate individual morality and maintained hypnotism's association with health. For most physicians, Myers' hopeful contemplation of humanity's spiritual evolution conflicted with widely perceived

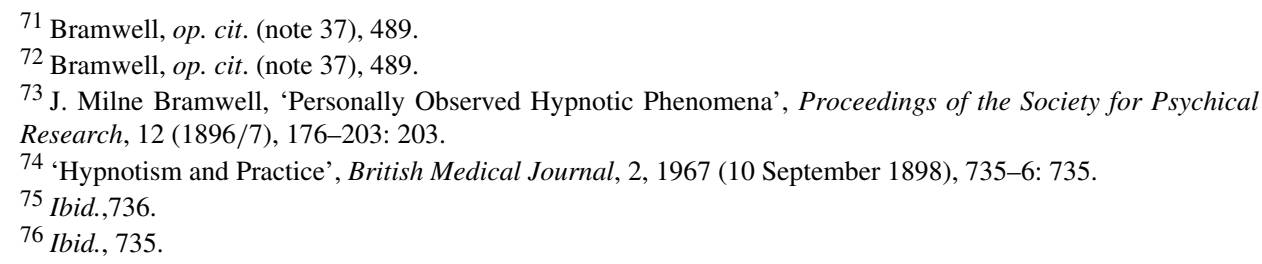


social problems in Britain in the late nineteenth century. ${ }^{77}$ Unlike Myers' 'subliminal self', suggestibility provided a language for understanding the perceived unruliness and irrationality of the lower classes, while it also provided an explanation for why such individuals posed a threat to middle-class social order. At the same time as suggestibility helped to explain the nature of Britain's social problems, it opened up a potential practical method for reforming and controlling the socially undesirable through still unexplored forms of 'education'. In the end, the suggestible subject more aptly corresponded to the disruptive influences in British society that numerous physicians were already engaged in medicalising.

\section{Conclusion}

Hypnotism hit a central nerve running through British society in the late nineteenth century. As a practice underwritten by the concept of suggestibility, it played into concerns about democratisation, the emergence of mass culture, and the difficulty of establishing a basis for morality in an increasingly secular age. The apparent phenomenon of the hypnotic 'rapport' exposed the seeming ambiguity of personal boundaries, questioned the inviolability of individual autonomy, and ultimately presented a threat to the stability of the Victorian social order. Furthermore, because the majority of hypnotism's medical supporters - with the notable exception of John Milne Bramwell - accepted Bernheim's doctrine of suggestibility and all it implied, even advocates of hypnotism were unable to mount a convincing case for the practice. No amount of proposed legal restrictions could overcome the seemingly endless possibilities for mental 'slavery' or the dangers associated with hypnotic influence. No amount of medical evidence demonstrating that hypnotism could be used to cure a variety of illnesses could persuade the majority of physicians that the hypnotic 'rapport' was a desirable, or even acceptable, relationship between two people. The argument for hypnotism could not be won.

Ironically, the rejection of hypnotism as a medical practice was a testament to its persuasiveness as a theory for understanding the problems of modern social life. Given its problematic implications, the theory of universal suggestibility provided a compelling framework for imagining social existence at a moment when a far-reaching re-orientation of social and political life appeared both inevitable and necessary. It made sense to physicians at the turn of the century, however committed they might be to an ideal of social progress rooted in individual rational autonomy. Although Ernest Hart asserted in 1893 that the hypnotic subject was 'not only born... but made', he retained the concept of suggestibility as a means to explaining how it was made. At once constructed and contested during the hypnotism debates, the suggestible hypnotic subject - and its accompanying consequences for social life - demonstrated an enormous intractability in refusing to be unmade, or remade into Myers' more profoundly moral subliminal self. As a symptom of tensions deeply rooted in the fabric of middle-class responses to social change at the turn of the century, physicians could not force the suggestible subject out of existence.

Beyond the context of medical therapeutics, universal suggestibility had tremendous appeal within the newly developing field of social psychology as the most fruitful basis for

\footnotetext{
77 John Cerullo has argued that Freud's theory of unconscious life 'prevailed' because his focus on the human tendency for destructive irrational behaviour helped to explain some of the most troubling aspects of early twentieth-century social life. Further, Cerullo argues that Freud offered a practical therapeutic method that strove to tame the irrational unconscious and promote civilised behaviour. John Cerullo, The Secularization of the Soul: Psychical Research in Modern Britain (Philadelphia: Institute for the Study of Human Issues, 1982).
} 
understanding 'modern' social life. The theory was widely taken up by leading crowd and social psychologists at the turn of the century to explain a wide range of irrational social phenomena, from fashion fads to religious revivals, financial panics, and the violence of mobs. By 1907, as Wilfred Trotter noted, suggestibility had replaced irrationality as 'the despair of the social reformer': 'Now the trouble is not irrationality, not a definite preference for unreason, but suggestibility - that is, a capacity for accepting reason or unreason if it comes from the proper source. ${ }^{78}$ As the capacity for independence of thought was being questioned in many quarters, and individual autonomy was increasingly seen as illusory, universal suggestibility signified an ever-present potential for social chaos. An apparently unavoidable fact of social life at the turn of the century, suggestibility could at best be only carefully managed. Medical participants in the hypnotism debate were keenly aware of these larger social implications.

For most physicians suggestibility was resistant to regulation, and the networks of hypnotic influence too diffuse to be patrolled. In the potential medical adoption of therapeutic hypnotism, not only were the trust and authority of physicians at stake, but also the social structure in which they were profoundly implicated. Hypnotism was in retreat from public medical discussion soon after its rediscovery not because it was perceived as therapeutically ineffective, or because its practice was considered too difficult to regulate professionally. Hypnotism was judged an impossible practice because it was seen as potentially destabilising and affirmed educated middle-class fears concerning the threat to lasting social stability in a modern democratic world. Physicians' rejection of hypnotism constituted an effort to preserve the Victorian social order. Moreover, it was rooted in an acknowledgement that, despite claims of progress, modern medicine was unable to provide a definitive solution to the inescapable problems which universal suggestibility implied. Solving the problem of the suggestible subject meant solving the many social problems that underwrote 'progress' in the late nineteenth century, and this was beyond the capacity of professional medicine. As a result, the medical debate over the adoption of hypnotism as a therapeutic practice foundered and effectively fell into a protracted silence by the end of the nineteenth century.

78 Trotter, op. cit. (note 58), 46. 